\title{
Thermal aromatic Claisen rearrangement and Strecker reaction of alkyl(allyl)-aryl ethers under green reaction conditions: Efficient and clean preparation of ortho-allyl phenols (naphthols) and alkyl(allyl)oxyarene-based $\gamma$-amino nitriles
}

\author{
Kheila N. Silgado-Gómez and Vladimir V. Kouznetsov* \\ Laboratorio de Química Orgánica y Biomolecular, CMN, Universidad Industrial de Santander, \\ Parque Tecnológico Guatiguará, Km 2 Vía Refugio, Piedecuesta 681011, Colombia·
}

\begin{abstract}
Chemical transformations of 13 diverse allyl(alkyl)-aryl ethers, easily prepared using Williamson reaction of different hydroxyarenes and allyl bromide and alkyl ( $n$-butyl, $n$-octyl) bromides, were studied. Thermal aromatic Claisen rearrangement of allyl-aryl ethers to obtain ortho-allyl phenols (naphthols) employing propylene carbonate as a nontoxic and biodegradable solvent was described for the first time. The use of this green solvent allowed to enhance notably product yields and reduce significantly the reaction time comparing with the use of 1,2-dichlorobenzene, toxic solvent, which is traditionally employed in this type of Claisen rearrangement. Three-component Strecker reaction of selected alkyl(allyl)-aryl ethers with formyl function on aryl fragment, piperidine and potassium cyanide in the presence of sulfuric acid supported on silica gel (SSA, $\left.\mathrm{SiO}_{2}-\mathrm{O}-\mathrm{SO}_{3} \mathrm{H}\right)$ under mild reaction conditions was used in the preparation of new $\gamma$-amino nitriles, analogues of alkaloid girgensohnine [2-(4-hydroxyphenyl)-2-(piperidin-1-yl)acetonitrile], a perspective biological model in the search for new insecticidal agrochemicals against Aedes aegypti. The use of SSA, an inexpensive and reusable solid catalyst, allowed to obtain new series of 2-[4-alkyl(allyl)oxyphenyl]-2-(piperidin-1-yl)acetonitriles in short time at room temperature with good yields.
\end{abstract}

Keywords: Substituted aryl ethers, Green chemistry, Claisen rearrangement, ortho-Allyl hydroxyarenes, Strecker reaction, $\alpha$-Amino nitriles

\section{Introduction}

Phenolics are the most prevalent class of metabolites in nature, and their distribution is almost ubiquitous, so it is not difficult to understand their biological and synthetic importance ${ }^{1}$. Among diverse phenolic compounds, simple ortho-allyl phenols and naphthols not only stand out as promising pharmacological agents and versatile synthetic intermediates, but as raw materials for the manufacture of a wide assortment of organic products ${ }^{2}$.

On the other hand, $\alpha$-amino nitriles, common precursors to natural and unnatural $\alpha$-amino acids, have a profound impact on bio-chemical sciences, serving as suitable models in pharmacological and biological research, inexpensive starting materials and valuable intermediates in chemical synthesis of vitally important heterocyclic and carbocyclic molecules ${ }^{3-5}$. Additionally, the $\alpha$-amino nitriles containing phenolic moiety has been found to occur in diverse alkaloids, for example, simple alkaloid *Corresponding author: Vladimir V. Kouznetsov Email address: vkuznechnik@gmail.com DOI: http://dx.doi.org/10.13171/mjc65/01711201245-kouznetsov girgensohnine [2-(4-hydroxyphenyl)-2-(piperidin1 -yl)acetonitrile] found in the green petals of the shrub Girgensohnia oppositiflora ${ }^{6,7}$. and some its synthetic analogs, for example, $\alpha$-amino nitrile with dimethoxyphenyl moiety A (Fig. 1) showed promising biological properties such as in vivo larvicidal activity against Aedes aegypti, the major vector of dengue fever, an endemic disease in America and Asia ${ }^{8}$.

Traditionally, ortho-allyl hydroxyarenes (phenols and naphthols) and $\alpha$-amino nitriles are prepared by use of the aromatic Claisen rearrangement and the Strecker reaction, respectively. Aromatic Claisen rearrangement, belonging to the $[3,3]$ sigmatropic rearrangements, is a valuable ortho specific functionalization of phenols, which are important both as substrates and as reagents ${ }^{9}$. Although there are different protocols on metal-catalyzed Claisen rearrangement ${ }^{10,11}$, this thermal aromatic Claisen rearrangement continues

Received October 15, 2017

Accepted, November 11, 2017

Published November 20, 2017 
to be very important for the construction of a carbon-carbon bond for allylated natural products ${ }^{1,12}$. The key precursors of this phenolic functionalization are allyl oxyarenes that can isomerize into $\mathrm{C}$-allyl hydroxyarenes with potential antioxidant properties ${ }^{13}$.

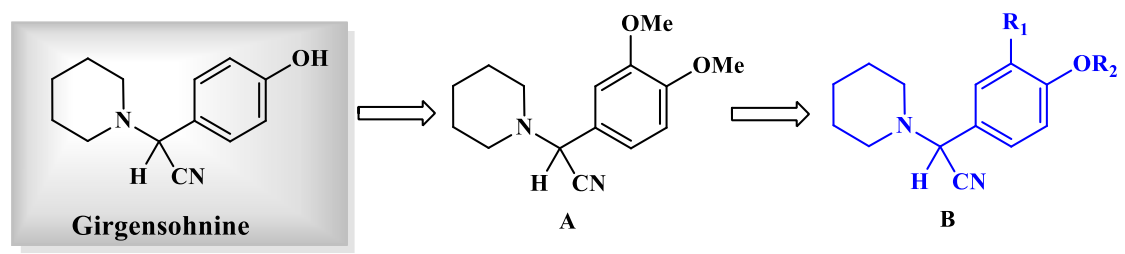

Figure 1. $\alpha$-Amino nitriles design inspired by natural molecule, girgensohnine alkaloid.

The Claisen rearrangement of allyl-aryl ethers can be realized under Lewis and Brönsted acids catalysis or thermally using different solvents such as toluene, dichlorobenzene, decalin, $\mathrm{N}, \mathrm{N}$-diethylaniline. The rearrangement is typical carried out at $150-300{ }^{\circ} \mathrm{C}$ and although their products are usually ortho isomers, para allylated phenols and benzofurans are often formed as side products.

Even though microwave-assisted aromatic Claisen rearrangement protocols have been developed, large-scaled procedures for the preparation of ortho-allyl phenols and naphthols are still based on thermal aromatic Claisen rearrangement protocols. While these are very simple, but these conditions have some drawbacks such as prolonged reaction times, use of toxic solvents (and catalysts) and high temperature regimes ${ }^{14}$.

The Strecker reaction of amines, aldehydes and cyanide source, which allows for rapidly preparing rapidly $\alpha$-amino nitriles, occurs generally in the presence of Lewis or Brönsted acids. In addition, cyanating agents employed in three-component Strecker reaction $\left(\mathrm{HCN}, \mathrm{KCN}, \mathrm{Et}_{2} \mathrm{AlCN}\right.$, $(\mathrm{EtO})_{2} \mathrm{P}(\mathrm{O}) \mathrm{CN}, \mathrm{Bu}_{3} \mathrm{SnCN}, \mathrm{Me}_{3} \mathrm{SiCN}$, and others) reagents have its serious drawbacks, e.g., some of which involve the intervention of metal catalysts, strong reaction conditions and cautiously handling, others are unstable and corrosive liquids, and some are very expensive products and sensitive to moisture ${ }^{15}$. Among this variety of acid catalysts and cyanide sources, several heterogeneous catalysts (polymer-supported $\mathrm{Sc}(\mathrm{OTf})_{3}$, montmorillonite KSF-clay, silica- $\mathrm{H}_{2} \mathrm{SO}_{4}$, heteropoly acid, and $\mathrm{NH}_{2} \mathrm{SO}_{3} \mathrm{H}$ or sulfated tungstate, among others), which are more advantageous in terms of catalyst/product separation and continuous production, and $\mathrm{KCN}$ stand out as simple and inexpensive reagents ${ }^{16}$.

Taking into account the above stated and as a part of our medicinal research program directed to the development of small molecule drug discovery, we started preliminary study on these topics paying attention to efficient and green protocols of classical thermal aromatic Claisen rearrangement and Strecker reaction, keeping in mind an irregular structure of girgensohnine alkaloid and their new analogs methoxy(alkyl- or allyloxy)arene-based $\alpha$-amino nitriles $\mathbf{B}$ (Fig. 1). Therefore, now we present our study, based on simple chemical transformations of alkyl(allyl)-aryl ethers that is focused in: $i$ ) prepare alkyl(allyl)oxybenzaldehydes, ii) develop an efficient and simple protocol for the preparation of ortho-allyl phenols and naphthols using thermal aromatic Claisen rearrangement of allyloxyarenes, and iii) obtain new girgensohnine analogs via acid-catalyzed three-component Strecker reaction. All this, are in order to contribute in generation of diverse methoxy(alkyl- or allyloxy) arene-based $\alpha$-amino nitriles for forthcoming bioscreenings of insecticidal or/and antioxidant activities.

\section{Results and Discussion}

The allyl(alkyl)-aryl ethers $\mathbf{4}$ and $\mathbf{5}$, needed in our study, were easily prepared using Williamson reaction of different hydroxyarenes $\mathbf{1}$ and allyl bromide 2 and alkyl ( $n$-butyl, $n$-octyl) bromides $\mathbf{3}$, respectively; all these are commercial, low-cost products (Scheme 1).

The Williamson synthesis usually involves the employment of organic solvents or with phasetransfer catalysts in the presence of a base followed by refluxing for several hours ${ }^{17,18}$. In general, this preparation of allyl(alkyl)-aryl ethers is a $\mathrm{S}_{\mathrm{N}} 2$ O-alkylation process, in which polar aprotic solvents (DMF, DMSO, acetone, DMSO, MeCN, etc.), works better ${ }^{17}$. However, according to the concepts of green chemistry, these solvents have harmful effects on the environment, and thus would be replaced ${ }^{19}$. Noteworthy, reports of the use of polar protic solvents such as methanol and ethanol in this type of transposition are few ${ }^{20}$. Therefore, we tested reaction of phenols $\mathbf{1}$ and bromides $\mathbf{2 , 3}$ in the presence of $\mathrm{K}_{2} \mathrm{CO}_{3}$ in boiling ethanol, which is still the most prevalent green solvent derived from natural or renewable resources. Our attempt was successful: 1. All most O-allyloxyarenes $\mathbf{4}$ were prepared with good to excellent yields (82-97\%) for 2-8 h; only one phenolic compound, O-allylated thymol 4d was obtained in moderate yields $(62 \%)$ after prolonged boiling (18 h); 
2. O-Butyl(octyl)phenols 5 were also produced in good yields (80-93\%), but this conversion was more extended than $\mathrm{O}$-allylated phenols (Table 1 ).<smiles>[Y]c1cc(O)c([R])c([R3])c1[R]</smiles><smiles>C=CCCC(C)C(=O)OCC(=O)O</smiles><smiles>[Y9]c1cc(OCC=C)c([R1])c([R3])c1[R3]</smiles>

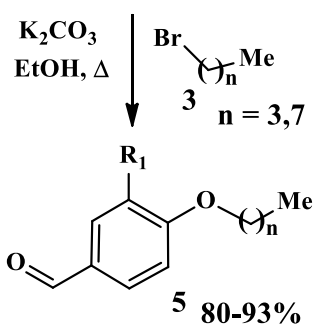

$$
\text { (1) }
$$<smiles>N#CC1CCCC[NH+]1C#N</smiles>

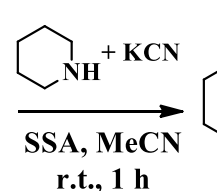<smiles>[R3]Oc1ccc(C(C)(C)N2CCCCC2)cc1[R3]</smiles><smiles>[R3]c1c([R])c([13CH3])c(O)c(CC=C)c1[Y6]</smiles>

DCB: $52-75 \%(10-40 \mathrm{~h})$

CP: $70-83 \%(1-6 \mathrm{~h})$

Scheme 1. Chemical transformations of allyl(alkyl)-aryl ethers $\mathbf{4}$ and $\mathbf{5}$ obtained by Williamson reaction.

Table 1. Preparation of allyl(alkyl)-aryl ethers $\mathbf{4}$ and $\mathbf{5}$ by Williamson reaction (allyl or alkyl bromides $\left./ \mathrm{K}_{2} \mathrm{CO}_{3} / \mathrm{EtOH} / \Delta\right)$.

\begin{tabular}{|c|c|c|c|c|c|c|}
\hline Entry & $\mathbf{R}_{\mathbf{1}}$ & $\mathbf{R}_{\mathbf{2}}$ & $\mathbf{R}_{\mathbf{3}}$ & $\mathbf{R} \mathbf{4}$ & Products & Yield, \% (time) \\
\hline 1 & $\mathrm{H}$ & $\mathrm{H}$ & $\mathrm{H}$ & $\mathrm{H}$ & $\mathbf{4 a}$ & $82(6 \mathrm{~h})$ \\
\hline 2 & $\mathrm{CH}=\mathrm{CH}-\mathrm{CH}=\mathrm{CH}$ & $\mathrm{H}$ & $\mathrm{H}$ & $\mathbf{4 b}$ & $78(7 \mathrm{~h})$ \\
\hline 3 & $\mathrm{H}$ & $\mathrm{CH}=\mathrm{CH}-\mathrm{CH}=\mathrm{CH}$ & $\mathrm{H}$ & $\mathbf{4 c}$ & $81(6 \mathrm{~h})$ \\
\hline 4 & $\mathrm{CHMe}$ & $\mathrm{H}$ & $\mathrm{H}$ & $\mathrm{Me}$ & $\mathbf{4 d}$ & $63(18 \mathrm{~h})$ \\
\hline 5 & $\mathrm{OMe}$ & $\mathrm{H}$ & $\mathrm{H}$ & $\mathrm{H}$ & $\mathbf{4 e}$ & $85(3 \mathrm{~h})$ \\
\hline 6 & $\mathrm{CHO}$ & $\mathrm{H}$ & $\mathrm{H}$ & $\mathrm{H}$ & $\mathbf{4 f}$ & $87(4 \mathrm{~h})$ \\
\hline 7 & $\mathrm{OMe}$ & $\mathrm{H}$ & $\mathrm{H}$ & $\mathrm{CHO}$ & $\mathbf{4 g}$ & $92(2 \mathrm{~h})$ \\
\hline 8 & $\mathrm{H}$ & $\mathrm{H}$ & $\mathrm{CHO}$ & $\mathrm{H}$ & $\mathbf{4 h}$ & $83(2 \mathrm{~h})$ \\
\hline 9 & $\mathrm{OMe}$ & $\mathrm{H}$ & $\mathrm{CHO}$ & $\mathrm{H}$ & $\mathbf{4 i}$ & $97(2 \mathrm{~h})$ \\
\hline 10 & $\mathrm{H}$ & $\mathrm{H}$ & $\mathrm{CHO}$ & $\mathrm{H}$ & $\mathbf{5 a}(\mathrm{n}=3)$ & $90(11 \mathrm{~h})$ \\
\hline 11 & $\mathrm{OMe}$ & $\mathrm{H}$ & $\mathrm{CHO}$ & $\mathrm{H}$ & $\mathbf{5 b}(\mathrm{n}=3)$ & $84(10 \mathrm{~h})$ \\
\hline 12 & $\mathrm{H}$ & $\mathrm{H}$ & $\mathrm{CHO}$ & $\mathrm{H}$ & $\mathbf{5 c}(\mathrm{n}=7)$ & $80(12 \mathrm{~h})$ \\
\hline 13 & $\mathrm{OMe}$ & $\mathrm{H}$ & $\mathrm{CHO}$ & $\mathrm{H}$ & $\mathbf{5 d}(\mathrm{n}=7)$ & $93(18 \mathrm{~h})$ \\
\hline
\end{tabular}

All products formed $\mathbf{4}$ and $\mathbf{5}$ were purified using column chromatography $\left(\mathrm{SiO}_{2}\right)$ eluting with different concentrations of petroleum ether:ethyl acetate to obtain pure substances as clean transparent oils. The structure of these simple products and its purity were confirmed by IR and MS spectra and by comparing their physical and spectral data with those reported in the literature ${ }^{12,21-23}$.

After the preparation and spectral characterization (MS and IR spectra) of 13 diverse O-alkylated phenols and naphthols, first we addressed to thermal aromatic Claisen rearrangement of allyl oxyarenes $\mathbf{4 a - i}$ as a simple and inexpensive procedure for the respective orthoallyl phenols and naphthols 6a-i, needed in our biological investigations. Searching for suitable green solvents 24,25 , we decided to use 1,2dichlorobenzene (DCB), toxic solvent, which is traditionally employed in this type of Claisen rearrangement and propylene carbonate
(CP, 4-methyl-1,3-dioxolan-2-one), nontoxic and bio-degradable solvent ${ }^{26}$ in our comparative study. Actually, propylene carbonate is widely used as a polar, aprotic solvent with high molecular dipole moment (4.9 D) in diverse chemical transformations ${ }^{27}$, but, to our knowledge, $\mathrm{CP}$ as solvent has not been used in Claisen rearrangement (Scheme 1). Results obtained during this study indicated that the use of propylene carbonate permitted to improve particularly product yields and reduce considerably the reaction time comparing with the use of 1,2-dichlorobenzene (Table 2). Although both protocols use high temperature regimes (DCB, $190{ }^{\circ} \mathrm{C}$ and $\mathrm{CP}$, $140^{\circ} \mathrm{C}$ ), new procedure based on $\mathrm{CP}$, green solvent stand out as a perspective method of preparing ortho-allyl phenols and naphthols that could be improved by use of microwave irradiation ${ }^{28}$. The structure of products $\mathbf{6 a - i}$ obtained and its purity were confirmed by IR and MS spectra. Their ${ }^{1} \mathrm{H}$ NMR chemical shift values were matched with literature ${ }^{12,21-23}$. 
Table 2. Comparative study on thermal aromatic Claisen rearrangement of allyloxyarenes 4a-i in 1,2-dichlorobenzene (DCB) and propylene carbonate (CP) for the preparation of ortho-allyl hydroxyarenes 6a-i.

\begin{tabular}{|c|c|c|c|c|c|c|c|}
\hline Entry & $\mathbf{R}_{\mathbf{1}}$ & $\mathbf{R}_{\mathbf{2}}$ & $\mathbf{R}_{\mathbf{3}}$ & $\mathbf{R}_{\mathbf{4}}$ & Product & \multicolumn{2}{|c|}{ Yield, \% } \\
\hline & & & & & $\mathbf{6}$ & DCB (time) & CP (time) \\
\hline 1 & $\mathrm{H}$ & $\mathrm{H}$ & $\mathrm{H}$ & $\mathrm{H}$ & $\mathbf{a}$ & $55(40 \mathrm{~h})$ & $73(5 \mathrm{~h})$ \\
\hline 2 & $\mathrm{CH}=\mathrm{CH}-\mathrm{CH}=\mathrm{CH}$ & $\mathrm{H}$ & $\mathrm{H}$ & $\mathbf{b}$ & $52(30 \mathrm{~h})$ & $73(1 \mathrm{~h})$ \\
\hline 3 & $\mathrm{H}$ & $\mathrm{CH}=\mathrm{CH}-\mathrm{CH}=\mathrm{CH}$ & $\mathrm{H}$ & $\mathbf{c}$ & $70(10 \mathrm{~h})$ & $80(1 \mathrm{~h})$ \\
\hline 4 & $\mathrm{CHMe}$ & $\mathrm{H}$ & $\mathrm{H}$ & $\mathrm{Me}$ & $\mathbf{d}$ & $\mathrm{nt}^{*}$ & $74(2 \mathrm{~h})$ \\
\hline 5 & $\mathrm{OMe}$ & $\mathrm{H}$ & $\mathrm{H}$ & $\mathrm{H}$ & $\mathbf{e}$ & $70(10 \mathrm{~h})$ & $77(4 \mathrm{~h})$ \\
\hline 6 & $\mathrm{CHO}$ & $\mathrm{H}$ & $\mathrm{H}$ & $\mathrm{H}$ & $\mathbf{f}$ & $\mathrm{nt}$ & $82(2 \mathrm{~h})$ \\
\hline 7 & $\mathrm{H}$ & $\mathrm{H}$ & $\mathrm{CHO}$ & $\mathrm{H}$ & $\mathbf{g}$ & $75(40 \mathrm{~h})$ & $80(6 \mathrm{~h})$ \\
\hline 8 & $\mathrm{OMe}$ & $\mathrm{H}$ & $\mathrm{CHO}$ & $\mathrm{H}$ & $\mathbf{h}$ & $\mathrm{nt}$ & $83(6 \mathrm{~h})$ \\
\hline 9 & $\mathrm{OMe}$ & $\mathrm{CHO}$ & $\mathrm{H}$ & $\mathrm{H}$ & $\mathbf{i}$ & $74(15 \mathrm{~h})$ & $70(4 \mathrm{~h})$ \\
\hline
\end{tabular}

* nt - not tested

Next, selected allyl-aryl ethers $\mathbf{4 h}, \mathbf{i}$ and alkylaryl ethers 5a-d containing a formyl function on aryl fragment were tested in three component Strecker reaction of piperidine and potassium cyanide in the presence of sulfuric acid supported on silica gel $\left(\mathrm{SSA}, \mathrm{SiO}_{2}-\mathrm{O}-\mathrm{SO}_{3} \mathrm{H}\right){ }^{29}$ in acetonitrile at room temperature (Scheme 1). Simple stirring of a threecomponent mixture for $60 \mathrm{~min}$ allowed the simple preparation of the needed products as stable white crystal solids purified by flash column chromatography on silica gel, using petroleum ether/ethyl acetate as eluent (Table 3). Structure of the obtained compounds 7a-f was confirmed strongly by common spectral methods. The IR spectra of $\alpha$-amino nitriles obtained showed the characteristic $\mathrm{C} \equiv \mathrm{N}$ bands appearing in the region of $2215-2298 \mathrm{~cm}^{-}$ ${ }^{1}$. In the ${ }^{1} \mathrm{H}$ NMR spectra of the amino nitriles $\mathbf{7 a}, \mathbf{b}$, the protons of the $\mathrm{O}-\mathrm{CH}_{2} \mathrm{CH}=\mathrm{CH}_{2}$, aromatic and piperidine rings, and $\mathrm{Ar}-\mathrm{CH}-\mathrm{N}_{\text {pipe }}$ fragments gave rise to very characteristic groups of signals. The singlet from a proton at $\mathrm{C}-4$ was observed in the region $\delta 4.88-5.25 \mathrm{ppm}$. A signal for two protons corresponding to the $\mathrm{O}-\mathrm{CH}_{2}$ methylene group appeared in the region $\delta 4.60-4.66 \mathrm{ppm}$. The two multiples between $\delta 5.17-5.31$ and $\delta 5.80-5.86 \mathrm{ppm}$ are due to the olefinic hydrogens, $-\mathrm{CH}_{2}=$ and $-\mathrm{CH}=$, respectively.

Their structures were also confirmed by MS, ${ }^{1} \mathrm{H}$ , ${ }^{13}$ C-NMR spectra. Noteworthy, SSA is an inexpensive and reusable solid catalyst. The ${ }^{1} \mathrm{H}$ NMR spectra of other pairs of O-alkylated aryl amino nitriles 7c,d and 7e,f showed a characteristic pattern for the aliphatic chain, in addition to a $\mathrm{CH}-\mathrm{N}$ proton singlet at $\delta 5.22-5.30 \mathrm{ppm}$ and an $\mathrm{O}-\mathrm{CH}_{2} \mathrm{R}$ methylene triplet $(J=4.7 \mathrm{~Hz})$ at $\delta 3.99-4.03 \mathrm{ppm}$

Table 3. Properties and yields of synthesized $\alpha$-amino nitriles 7a-f. ${ }^{\text {a }}$

\begin{tabular}{|c|c|c|c|c|c|c|c|c|}
\hline Product & $\mathbf{R}_{1}$ & $\mathbf{R}_{5}$ & Yield, \% & $\mathrm{Mp},{ }^{\circ} \mathrm{C}$ & MW, g/mol & cLogP $P^{b}$ & TPSA $^{c}$ & pKa \\
\hline $7 \mathbf{a}$ & $\mathrm{H}$ & Allyl & 50 & $84-86$ & 256.35 & 3.318 & 36.264 & 5.72 \\
\hline $7 b$ & $\mathrm{OMe}$ & Allyl & 67 & $83-85$ & 286.37 & 2.908 & 45.498 & 5.63 \\
\hline $7 c$ & $\mathrm{H}$ & $\mathrm{n}-\mathrm{Bu}$ & 52 & $86-88$ & 272.39 & 4.112 & 36.264 & 5.72 \\
\hline $7 d$ & $\mathrm{OMe}$ & $\mathrm{n}-\mathrm{Bu}$ & 55 & $97-99$ & 302.41 & 3.702 & 46.498 & 5.64 \\
\hline $7 e$ & $\mathrm{H}$ & n-Octyl & 51 & $120-122$ & 328.25 & 6.133 & 35.264 & 5.72 \\
\hline $7 f$ & $\mathrm{OMe}$ & n-Octyl & 70 & $132-135$ & 358.52 & 5.723 & 45.498 & 5.64 \\
\hline
\end{tabular}

a Theoretical values cLogP, PTSA and pKa were calculated using commercially available ChemDraw 15.0 program; ${ }^{\mathrm{b}} \mathrm{cLogP}=n$-octanol/water partition coefficient; ${ }^{\mathrm{c}} \mathrm{TPSA}=$ Topological polar surface area.

Taking into consideration that the field of agrochemical discovery could benefit from treatment of pesticide-likeness (agrochemicallikeness) ${ }^{30,31}$, we realized a small in silico calculation study evaluating some parameters (cLogP, TPSA and $\mathrm{pKa}$ ) that can predict membrane permeability, lipophilicity and basicity of the synthetic molecule. From Table 3, it should be noted that 1. All compounds obtained possess favorable values of TPSA (36.26 - 45.49) and $\mathrm{pKa}$ for agrochemical substances; 2 .

The values of calculated partition coefficient (cLog P) are above the lipophilicity optimum interval $(0<\operatorname{cog} \mathrm{P}<3)$. This means that all synthetized $\alpha$-amino nitriles molecules have a low water solubility character (cLog P > 2.90-6.13) that could compromise the absorption properties of these compounds. However, according to these parameters, the $\alpha$-amino nitriles obtained $7 \mathbf{a}-\mathbf{f}$ could penetrate the cuticle of insects, especially the compounds 7e,f with the hydrophobic portion.

\section{Conclusion}

Studying chemical transformations of diverse allyl(alkyl)-aryl ethers, prepared using Williamson reaction, it was shown that thermal aromatic 
Claisen rearrangement of allyl-aryl ethers to obtain ortho-allyl phenols (naphthols) can be promoted considerably by propylene carbonate, green, nontoxic and biodegradable medium. The use of this green solvent allowed to enhance notably product yields and reduce significantly the reaction time comparing with the use of 1,2dichlorobenzene. Also it demonstrated that simple three-component Strecker reaction of selected substituted benzaldehydes, piperidine and potassium cyanide in the presence of sulfuric acid supported on silica gel $\left(\mathrm{SSA}, \mathrm{SiO}_{2}-\mathrm{O}-\mathrm{SO}_{3} \mathrm{H}\right)$ under mild green reaction conditions allowed preparing easily new $\alpha$-amino nitriles, analogues of alkaloid girgensohnine, interesting molecules in the search for new insecticidal agrochemicals against Aedes aegypti. According to the in-silico calculation study, all almost the $\alpha$-amino nitriles obtained are moderate lipophilic compounds with favorable values of TPSA for agrochemical substances. Biological tests of these compounds are currently under study in our laboratories and their results will be published elsewhere in near future.

\section{Acknowledgements}

This work was supported by COLCIENCIAS (project No. RC-007-2017, Cod. 110274558597).

\section{Experimental}

The melting points (uncorrected) were determined on a Fisher-Johns melting point apparatus. Infrared (FT-IR) spectra were recorded on a Lumex Infralum FT-02 spectrometer, $\gamma_{\max }$ in $\mathrm{cm}^{-1}$. Bands are characterized according to the functional group. ${ }^{1} \mathrm{H}-\mathrm{NMR}$ spectra were obtained with a Bruker AM400 spectrometer $(400 \mathrm{MHz})$. Data were reported as follows: chemical shift, integration, multiplicity ( $\mathrm{s}$ $=$ singlet, $\mathrm{d}=$ doublet, $\mathrm{t}=$ triplet, $\mathrm{dd}=$ doublet of doublets, $\mathrm{dt}=$ doublet of triplets, $\mathrm{ddd}=$ doublet of doublet of doublets, $\mathrm{td}=$ triplet of doublets, $\mathrm{qd}=$ quartet of doublets, $\mathrm{m}=$ multiplet), coupling constants $(\mathrm{Hz})$ and proton assignation. ${ }^{13} \mathrm{C}-\mathrm{NMR}$ spectra were obtained with a Bruker AM-400 (100 MHz) spectrometer with complete proton decoupling. Chemical shifts were reported in ppm ( $\delta)$ relative to the solvent peak $\left(\mathrm{CDCl}_{3}, 7.24 \mathrm{ppm}\right.$ for ${ }^{1} \mathrm{H}$ and $77.23 \mathrm{ppm}$ for ${ }^{13} \mathrm{C}$ ). A Hewlett Packard 5890a Series II Gas Chromatograph interfaced to an HP 5972 Mass Selective Detector (MSD) with an HP MS ChemStation Data system was used for MS identification at $70 \mathrm{eV}$ using a $60 \mathrm{~m}$ capillary column coated with HP-5 [5\%-phenylpoly (dimethylsiloxane)]. Elemental analyses were performed on a PerkinElmer 2400 Series II analyzer with theoretical values of \pm 0.4 . The workup for the reactions, extraction, and purification procedures in column chromatography were carried out using reactants and reagent grade solvents (purchased from Merck, Sigma-Aldrich and J.T.
Baker). Thin-layer chromatography (TLC) was performed using Silufol UV254 precoated plates $(0.25 \mathrm{~mm})$. UV light of $254 \mathrm{~nm}$ was used to observe components and iodine vapor was used for revealing. Column chromatography was performed using silica gel column as solid support (Merck, silica gel 60 (0.063 - $0.200 \mathrm{~mm}) 70-230 \mathrm{mesh})$ using as eluents solvent mixtures of petroleum ether and ethyl acetate.

\section{Typical Procedure for Synthesis of Allyl(alkyl)- Aryl Ethers 4 and 5}

A mixture of phenol 1 (1 mmol), allyl bromide 2 or alkyl bromides $3(1 \mathrm{mmol})$ and $\mathrm{Na}_{2} \mathrm{CO}_{3}(2 \mathrm{mmol})$ in ethanol $(10 \mathrm{~mL})$ was heated to reflux for the required time as indicated in Table 1 . The progress of the reaction was monitored by TLC. Standard work-up with filtration of reaction mixture, ethanol evaporation and ethyl acetate extraction followed by simple column chromatography provided the pure product. All products listed in Table 1 were known in the literature and were identified by comparison of their GC-MS, FT-IR, and ${ }^{1} \mathrm{H}$ NMR with literature data.

\section{Typical Procedure for Thermal Aromatic Claisen rearrangement of Allyloxyarenes 4a-i}

A solution of allyl compound $\mathbf{4 a - 4 i}(10.00 \mathrm{mmol})$ in 1,2-dichlorobenzene $(10 \mathrm{~mL})$ or in propylene carbonate $(5 \mathrm{~mL})$ was subjected to heating $\left(190{ }^{\circ} \mathrm{C}\right.$ for DCB and $140{ }^{\circ} \mathrm{C}$ for PC). The progress of the reaction was monitored by TLC. Upon completion of the reaction, the solvent was evaporated and the reaction crude was purified by column chromatography (CC) on silica gel using a mixture of hexane and ethyl acetate as the eluent to obtain the rearranged product 5a-5i. All products listed in Table 2 were known in the literature and were identified by comparison of their GC-MS, FT-IR, and ${ }^{1} \mathrm{H}$ NMR with literature data.

\section{Typical Procedure for Synthesis of $\alpha$-Amino nitriles $7 \mathbf{a}-\mathbf{f}$}

Using a $50 \mathrm{~mL}$ round-bottom flask, benzaldehyde ethers 4h,i, 5a-d (3 mmol) and piperidine (1.5 mmol) were dissolved with a magnetic stirrer in acetonitrile $(10 \mathrm{~mL})$ and kept stirring for 30 minutes at room temperature. Subsequently, KCN (100 mg, $3 \mathrm{mmol}$ ) and $0.80 \mathrm{~g}$ of SSA catalyst were added to the flask. Then, the resulting suspension was stirred for $60 \mathrm{~min}$ (TLC control) and filtered. The resulting filtrate was quenched with saturated sodium bicarbonate solution (10 mL, $1 \mathrm{M})$, extracted with ethyl acetate $(3 \times 10 \mathrm{~mL})$, dried $\left(\mathrm{Na}_{2} \mathrm{SO}_{4}\right)$ and concentrated. The obtained crude product was purified with silica gel column chromatography $\left(\mathrm{SiO}_{2}\right)$ eluting with different concentrations of petroleum ether:ethyl acetate to 
obtain pure $\alpha$-amino nitrile compounds 7a-f as white stable solid with well-defined melting points (Table 3).

\section{2-(4-(Allyloxy)phenyl)-2-(piperidin-1-yl)}

acetonitrile7a. Evaluated by hexane: ethyl acetate (10:1) system. Yield 50\%. White solid, mp. 84-86 ${ }^{\circ} \mathrm{C}$. IR (KBr), $v \mathrm{~cm}^{-1}$ : 2854, 2298, 1604, 1511, 1465 , 1249.

${ }^{1} \mathrm{H}$ NMR (400 MHz, $\left.\mathrm{CDCl}_{3}\right), \delta_{(\mathrm{ppm})}: 7.17(2 \mathrm{H}, \mathrm{d}, J=$ $\left.7.5 \mathrm{~Hz}, \mathrm{H}_{\mathrm{Ar}}\right), 6.87\left(2 \mathrm{H}, \mathrm{d}, J=7.5 \mathrm{~Hz}, \mathrm{H}_{\mathrm{Ar}}\right), 5.86$ $(1 \mathrm{H}, \mathrm{m},-\mathrm{CH}=), 5.20(1, \mathrm{~s},-\mathrm{CH}-\mathrm{CN}), 5.16(2 \mathrm{H}, \mathrm{m}$, $\left.=\mathrm{CH}_{2}\right), 4.60\left(2 \mathrm{H}, \mathrm{m},-\mathrm{O}-\mathrm{CH}_{2}-\right), 3.09\left(4 \mathrm{H}, \mathrm{m}, \mathrm{H}_{\text {Pipe }}\right)$, 1.67 (4H, m, $\left.\mathrm{H}_{\text {Pipe }}\right), 1.58$ (2, m, $\left.\mathrm{H}_{\text {Pipe }}\right)$.

${ }^{13} \mathrm{C}$ NMR (101 MHz, $\left.\mathrm{CDCl}_{3}\right), \delta_{(\mathrm{ppm})}: 155.6,134.5$, $128.5,128.4,123.7,117.5,116.7,115.7,115.71$, 70.1, 64.7, 51.3 (2C), 24.7 (2C), 23.4.

CG-MS: m/z (EI, \%): $256\left(\mathrm{M}^{+}, 30\right), 172$ (90), 84 (30), 41 (100).

Anal. Calcd for $\mathrm{C}_{16} \mathrm{H}_{20} \mathrm{~N}_{2} \mathrm{O}$ : C, 74.97; H, 7.86; N, 10.93. Found: C, 74.68; H, 7.97; N, 10.76.

\section{2-(4-(Allyloxy)-3-methoxyphenyl)-2-(piperidin-1-}

$\boldsymbol{y l}$ )acetonitrile $\mathbf{7 b}$. Evaluated by hexane: ethyl acetate $(5: 1)$ system. Yield $67 \%$. White solid, mp. $83-85{ }^{\circ} \mathrm{C}$. IR $(\mathrm{KBr}), v \mathrm{~cm}^{-1}$ : 2931, 2215, 1589, $1511,1465,1265$.

${ }^{1} \mathrm{H}$ NMR $\left(400 \mathrm{MHz}, \mathrm{CDCl}_{3}\right), \delta_{(\mathrm{ppm})}: 6.85(1 \mathrm{H}, \mathrm{d}$, $\left.J=6.8 \mathrm{~Hz}, 5-\mathrm{H}_{\mathrm{Ar}}\right), 6.84\left(1 \mathrm{H}, \mathrm{s}, 2-\mathrm{H}_{\mathrm{Ar}}\right), 6.81(1 \mathrm{H}, \mathrm{d}$, $\left.J=6.9 \mathrm{~Hz}, 6-\mathrm{H}_{\mathrm{Ar}}\right), 5.86(1 \mathrm{H}, \mathrm{m},-\mathrm{CH}=), 5.16(2 \mathrm{H}$, $\left.\mathrm{m},=\mathrm{CH}_{2}\right), 4.88(1 \mathrm{H}, \mathrm{s},-\mathrm{CH}-\mathrm{CN}), 4.60(2 \mathrm{H}, \mathrm{d}, \quad J$ $\left.=6.3 \mathrm{~Hz},-\mathrm{O}-\mathrm{CH}_{2}-\right), 3.81(3 \mathrm{H}, \mathrm{s}, \mathrm{OMe}), 2.54(4 \mathrm{H}$, m, $\left.\mathrm{H}_{\text {Pipe }}\right), 1.66$ (4H, m, $\left.\mathrm{H}_{\text {Pipe }}\right), 1.61$ (2H, m, $\left.\mathrm{H}_{\text {Pipe }}\right)$.

${ }^{13} \mathrm{C}$ NMR (101 MHz, $\left.\mathrm{CDCl}_{3}\right), \delta_{(\mathrm{ppm})}: 149.6,142.6$, $134.7,123.7,121.0,118.2,117.5,116.7,109.2$, 71.2, 65.5, 56.8, 51.3 (2C), 24.7 (2C), 23.42.

GC-MS: m/z (EI, \%): $286\left(\mathrm{M}^{+\cdot}, 10\right), 202$ (60), 162 (25), 84 (100).

Anal. Calcd for $\mathrm{C}_{17} \mathrm{H}_{22} \mathrm{~N}_{2} \mathrm{O}_{2}$ : C, 71.30; H, 7.74; N, 9.78. Found: C, 71.17; H, 7.94; N, 9.63

\section{2-(4-Butoxyphenyl)-2-(piperidin-1-yl)acetonitrile}

7c. Evaluated by hexane: ethyl acetate (10:1) system. Yield 52\%. White solid, mp. 86-88 ${ }^{\circ} \mathrm{C}$. IR $(\mathrm{KBr}), v \mathrm{~cm}^{-1}: 2933,1523,1465,1265$.

${ }^{1} \mathrm{H}$ NMR $\left(400 \mathrm{MHz}, \mathrm{CDCl}_{3}\right), \delta_{(\mathrm{ppm})}: 7.27(2 \mathrm{H}, \mathrm{d}$, $\left.J=7.3 \mathrm{~Hz}, \mathrm{H}_{\mathrm{Ar}}\right), 6.92\left(2 \mathrm{H}, \mathrm{d}, J=7.5 \mathrm{~Hz}, \mathrm{H}_{\mathrm{Ar}}\right), 5.22$ $(1 \mathrm{H}, \mathrm{s},-\mathrm{CH}-\mathrm{CN}), 3.99\left(2 \mathrm{H}, \mathrm{t}, J=4.7 \mathrm{~Hz},-\mathrm{OCH}_{2}-\right)$, $2.65\left(4 \mathrm{H}, \mathrm{dt}, J=5.3 \mathrm{~Hz}, \mathrm{H}_{\text {Pipe }}\right), 1.73(2 \mathrm{H}, \mathrm{m}$, $\left.\mathrm{CH}_{2 \text { butyl }}\right), 1.65$ (4H, m, H $\left.\mathrm{H}_{\text {Pipe }}\right), 1.63$ (2H, m, $\mathrm{H}_{\text {Pipe }}$ ), $1.44\left(2 \mathrm{H}, \mathrm{m}, \mathrm{CH}_{2 \text { butyl }}\right), 0.99\left(3 \mathrm{H}, \mathrm{m},-\mathrm{CH}_{3 \text { butyl }}\right)$.

${ }^{13} \mathrm{C}$ NMR $\left(101 \mathrm{MHz}, \mathrm{CDCl}_{3}\right), \delta_{(\mathrm{ppm})}: 155.8,128.8$ (2C), 123.66, 116.7, 115.14 (2C), 69.8, 64.7, 51.25 (2C), 30.5, 24.7 (2C), 23.4, 19.9, 14.0.

GC-MS: m/z (EI, \%): $272\left(\mathrm{M}^{+\cdot}, 20\right), 188$ (45), 132 (100), 84 (20).

Anal. Calcd for $\mathrm{C}_{17} \mathrm{H}_{24} \mathrm{~N}_{2} \mathrm{O}$ : C, 74.96; H, 8.88; N, 10.28. Found: C, 74.76; H, 8.97; N, 10.05 .

2-(4-Butoxy-3-methoxyphenyl)-2-(piperidin-1yl)acetonitrile $7 \boldsymbol{d}$. Evaluated by hexane: ethyl acetate (10:1) system. Yield 55\%. White solid, mp.
97-99 ${ }^{\circ} \mathrm{C}$. IR (KBr), $v \mathrm{~cm}^{-1}: 2945,1511,1465$, 1265.

${ }^{1} \mathrm{H}$ NMR (400 MHz, $\left.\left.\mathrm{CDCl}_{3}\right), \delta_{(\mathrm{ppm})}\right) 7.07(1 \mathrm{H}, \mathrm{s}, 2-$ $\left.\mathrm{H}_{\mathrm{Ar}}\right), 7.03\left(1 \mathrm{H}, \mathrm{d}, J=6.7,5-\mathrm{H}_{\mathrm{Ar}}\right), 7.02(1 \mathrm{H}, \mathrm{d}$, $\left.J=6.6 \mathrm{~Hz}, 6-\mathrm{H}_{\mathrm{Ar}}\right), 5.25(1 \mathrm{H}, \mathrm{s},-\mathrm{CH}-\mathrm{CN}), 4.01(2 \mathrm{H}$, $\left.\mathrm{t}, J=4.4 \mathrm{~Hz},-\mathrm{OCH}_{2 \text { butyl }}\right), 3.83(3 \mathrm{H}, \mathrm{s}, \mathrm{OMe}), 2.54$ ( $\left.4 \mathrm{H}, \mathrm{dt}, J=5.5 \mathrm{~Hz}, \mathrm{H}_{\text {Pipe }}\right), 1.75\left(2 \mathrm{H}, \mathrm{m}, \mathrm{CH}_{2 \text { butyl }}\right)$, 1.67 (4H, m, $\left.\mathrm{H}_{\text {Pipe }}\right), 1.58$ (2H, m, $\left.\mathrm{H}_{\text {Pipe }}\right), 1.42(2 \mathrm{H}$, $\left.\mathrm{m}, \mathrm{CH}_{2 \text { butyl }}\right), 1.00\left(3 \mathrm{H}, \mathrm{t}, J=6.5 \mathrm{~Hz},-\mathrm{CH}_{3 \text { butyl }}\right)$.

${ }^{13} \mathrm{C}$ NMR $\left(101 \mathrm{MHz}, \mathrm{CDCl}_{3}\right), \delta_{(\mathrm{ppm})}: 149.5,142.8$, 123.8, 121.1, 118.1, 116.7, 108.9, 70.6, 65.5, 56.8, 51.3 (2C), 30.5, 24.7 (2C), 23.4, 19.9, 14.0.

GC-MS: m/z (EI, \%): $302\left(\mathrm{M}^{+\cdot}, 1\right), 272$ (30), 188 (55), 132 (100), 84 (25).

Anal. Calcd for $\mathrm{C}_{18} \mathrm{H}_{26} \mathrm{~N}_{2} \mathrm{O}_{2}: \mathrm{C}, 71.49 ; \mathrm{H}, 8.67 ; \mathrm{N}$, 9.26. Found: C, 71.23; H, 8.98; N, 9.35.

\section{2-(4-(Octyloxy)phenyl)-2-(piperidin-1-yl)}

acetonitrile $7 \boldsymbol{e}$. Evaluated by hexane: ethyl acetate (10:1) system. Yield 51\%. White solid, mp. 120$122{ }^{\circ} \mathrm{C}$. IR (KBr), $v \mathrm{~cm}^{-1}: 2932,1532,1265$.

${ }^{1} \mathrm{H}$ NMR (400 MHz, $\left.\mathrm{CDCl}_{3}\right), \delta_{(\mathrm{ppm})}: 7.27(2 \mathrm{H}, \mathrm{d}$, $\left.J=7.6 \mathrm{~Hz}, \mathrm{H}_{\mathrm{Ar}}\right), 6.92\left(2 \mathrm{H}, \mathrm{d}, J=7.4 \mathrm{~Hz}, \mathrm{H}_{\mathrm{Ar}}\right), 5.24$ $(1, \mathrm{~s},-\mathrm{CH}-\mathrm{CN}), 3.95\left(2 \mathrm{H}, \mathrm{t}, J=7.5 \mathrm{~Hz},-\mathrm{OCH}_{2 \mathrm{octyl}}\right)$, $2.52\left(4 \mathrm{H}, \mathrm{dt}, \mathrm{J}=5.3 \mathrm{~Hz}, \mathrm{H}_{\text {Pipe }}\right), 1.73(2 \mathrm{H}, \mathrm{m},-$ $\left.\mathrm{CH}_{2 \text { octyl }}\right), 1.66$ (4H, m, H $\left.\mathrm{H}_{\text {Pipe }}\right), 1.57$ (2H, m, H $\mathrm{H}_{\text {Pipe }}$ ), $1.31\left(10 \mathrm{H}, \mathrm{m},-\mathrm{CH}_{2 \text { octyl }}\right), 0.99(3 \mathrm{H}, \mathrm{t}, J=6.5 \mathrm{~Hz}$, $\left.\mathrm{CH}_{3 \text { octyl }}\right)$.

${ }^{13} \mathrm{C}$ NMR $\left(101 \mathrm{MHz}, \mathrm{CDCl}_{3}\right), \delta_{(\mathrm{ppm})}: 155.8,128.8$ (2C), 123.7, 116.7, 115.1 (2C), 69.6, 64.7, 51.25 (2C), 31.7, 29.1, 28.9, 28.7, 26.5, 24.7 (2C), 23.4, 22.9, 14.0 .

GC-MS: m/z (EI, \%): $328\left(\mathrm{M}^{+*}, 1\right), 272$ (30), 188 (55), 132 (100), 84 (25).

Anal. Calcd for $\mathrm{C}_{21} \mathrm{H}_{32} \mathrm{~N}_{2} \mathrm{O}$ : C, 76.78; H, 9.82; N, 8.53. Found: C, 76.56; H, 9.61; N, 8.79.

2-(3-Methoxy-4-(octyloxy)phenyl)-2-(piperidin-1-

$\boldsymbol{y l}$ )acetonitrile $7 \boldsymbol{f}$. Evaluated by hexane: ethyl acetate (10:1) system. Yield 70\%. White solid, mp. 132-135 ${ }^{\circ} \mathrm{C}$. IR (KBr), $v \mathrm{~cm}^{-1}: 2931,2215,1511$, $1465,1265$.

${ }^{1} \mathrm{H}$ NMR $\left(400 \mathrm{MHz}, \mathrm{CDCl}_{3}\right), \delta_{(\mathrm{ppm})}: 7.03(3 \mathrm{H}, \mathrm{m}$, $\left.\mathrm{H}_{\mathrm{Ar}}\right), 5.30(1, \mathrm{~s},-\mathrm{CH}-\mathrm{CN}), 4.01(2 \mathrm{H}, \mathrm{t}, J=4.6 \mathrm{~Hz}$, $\left.\mathrm{OCH}_{2 \text { octyl }}\right), 3.83(3 \mathrm{H}, \mathrm{s}, \mathrm{OMe}), 2.65(4 \mathrm{H}, \mathrm{dt}, J=5.2$ $\left.\mathrm{Hz}, \mathrm{H}_{\text {Pipe }}\right), 1.75\left(2 \mathrm{H}, \mathrm{m},-\mathrm{CH}_{2 \text { octyl }}\right), 1.65(4 \mathrm{H}, \mathrm{m}$, $\left.\mathrm{H}_{\text {Pipe }}\right), 1.63$ (2H, m, H $\left.\mathrm{H}_{\text {Pipe }}\right), 1.34$ (10H, m, $\left.-\mathrm{CH}_{2 \text { octyl }}\right)$, $0.99\left(3 \mathrm{H}, \mathrm{t}, J=6.6 \mathrm{~Hz},-\mathrm{CH}_{3 \text { octyl }}\right)$.

${ }^{13} \mathrm{C}$ NMR $\left(101 \mathrm{MHz}, \mathrm{CDCl}_{3}\right), \delta_{(\mathrm{ppm})}: 149.5,142.7$, $123.8,121.1,118.1,116.7,108.9,70.3,65.5,56.8$, 51.3 (2C), 31.6, 29.1, 28.9, 28.7, 26.5, 24.7 (2C), 23.4, 22.9, 14.0 .

GC-MS: m/z (EI, \%): $358\left(\mathrm{M}^{+\cdot}, 1\right), 272$ (30), 188 (55), 132 (100), 84 (25).

Anal. Calcd for $\mathrm{C}_{22} \mathrm{H}_{34} \mathrm{~N}_{2} \mathrm{O}_{2}$ : C, 73.70; H, 9.56; N, 7.81; O, 8.92. Found: C, 73.85; H, 9.34; N, 7.96.

\section{References}

1- The Chemistry of Phenols; ed. by Z. Rappoport; WileyVCH: New York, 2003, 1605 p. 
2- N. Balasundram, K. Sundram, S. Samman, Phenolic compounds in plants and agriindustrial by-products: Antioxidant activity, occurrence, and potential uses, Food Chem., 2006, 99, 191-203.

3- J. H. P. Tyman, Synthetic and Natural Phenols; Elsevier: New York, 1996, 699 p.

4- Y. M. Shafran, V. A. Bakulev, V. S. Mokrushin, Synthesis and properties of $\gamma$-Aminonitriles, Russ. Chem. Rev., 1989, 58, 148-162.

5- N. Otto, T. Opatz, Heterocycles from $\gamma$-Aminonitriles. Chem. Eur. J., 2014, 20, 1-15.

6- N. K. Yurashevsky, N. L. Stepanova, Investigation of alkaloids of Girgensohnia oppositiflora, J. Gen. Chem. USSR, 1946, 16, 141-144.

7- L. Y. Vargas-Méndez, V. V. Kouznetsov, First Girgensohnine Analogs Prepared Through $\mathrm{InCl}_{3}$-catalyzed Strecker Reaction and their Bioprospection. Curr. Org. Synth., 2013, 10, 969-973.

8- A. L. Carreño Otero, L. Y. Vargas-Méndez, L. J. E Duque, V. V. Kouznetsov, Design, synthesis, acetylcholinesterase inhibition and larvicidal activity of girgensohnine analogs on Aedes aegypti, vector of dengue fever, Eur. J. Med. Chem., 2014, 78, 392-400.

9- A. M. M. Castro, Claisen Rearrangement over the Past Nine Decades, Chem. Rev., 2004, 104, 2939-3002.

10- K. C. Majumdar, S. Alam, B. Chattopadhyay, Catalysis of the Claisen rearrangement, Tetrahedron, 2008, 64, 597-643.

11- V. H. Grant and B. Liu, Iridium(III)-catalyzed tandem Claisen rearrangement-intramolecular hydroaryloxylation of aryl allyl ethers to form dihydrobenzofuran, Tetrahedron Lett., 2005, 46, 1237-1239.

12- F. C. Gozzo, S. A. Fernandes, D. C. Rodrigues, M. N. Eberlin, A. J. Marsaioli, Regioselectivity in Aromatic Claisen Rearrangements, J. Org. Chem., 2003, 68, 5493-5499.

13- R. Aeschbach, J. L. Liger, B. C. Scott, A. Murcia, J. Butler, B. Halliwell, O. T. Aruoma, Antioxidant action of thymol, carvacrol, 6gingerol, zingerone and hydroxytyrosol, Food Chem. Toxicol., 1994, 32, 31-36.

14- M. Yamaguchi, Synthetic uses of phenols, In The Chemistry of Phenols; ed. by $Z$. Rappoport; WileyVCH: New York, 2003, pp. 661-712.

15- R. O. Duthaler, Recent developments in the stereoselective synthesis of $\alpha$-aminonitriles, Tetrahedron, 1994, 50, 1539-1650.

16- K. Niknam, D. Saberi, M. N. Sefat, Silicabonded S-sulfonic acid: an efficient and recyclable solid acid catalyst for the threecomponent synthesis of $\alpha$-amino nitriles, Tetrahedron Lett., 2010, 51, 2959-2962.
17- J. March, March's Advanced Organic Chemistry, Reaction, Mechanism, and Structure, 5th ed., John Wiley \& Sons: New York, 2001, pp. 477-478.

18- J. J. Li, Name Reactions, 2d ed., Springler: Berlin, 2003, pp. 437.

19- Y. Peng and G. Song, Combined microwave and ultrasound assisted Williamson ether synthesis in the absence of phase-transfer catalysts, Green Chem., 2002, 4, 349-351.

20- S. Xiao, Y. He, G. Xu, Q. Liu, Investigation on Claisen rearrangement of allyl phenyl ethers in near-critical water, Res. Chem. Intermed., 2015, 41, 3299-3305.

21- J. C. Lee, J. Y. Yuk, S. H. Cho, Facile Synthesis of Alkyl Phenyl Ethers Using Cesium Carbonate, Synth. Commun., 1995, 25, 1367-1370.

22- M. Kazemia, Z. Noori, H. Kohzadi. A mild and efficient procedure for the synthesis of ethers from various alkyl halides, Iran. Chem. Commun., 2013, 1, 43-50.

23- S. H. Reich, M. Melnick, M. J. Pino, M. A. M. Fuhry, A. J. Trippe, K. Appelt, J. F. Davies, II, B.-W. Wu, L. Musick, J. Med. Chem., 1996, 39, 2781-2794.

24- P. G. Jessop, Searching for green solvents, Green Chem., 2011, 13, 1391-1398.

25- M. Sato, N. Otabe, T. Tuji, K. Matsushima, H. Kawanami, M. Chatterjee, T. Yokoyama, Y. Ikushima, T. M. Suzuki, Highly-selective and high-speed Claisen rearrangement induced with subcritical water microreaction in the absence of catalyst, Green Chem., 2009, 11, 763-766.

26- J. H. Clements, Reactive Applications of Cyclic Alkylene Carbonates, Ind. Eng. Chem. Res. 2003, 42, 663-674.

27- C. Beattie, M. North, P. Villuendas, ProlineCatalysed Amination Reactions in Cyclic Carbonate Solvent, Molecules, 2011, 16, 34203432.

28- S. Kotha, K. Mandal, A. C. Deb, S. Banerjee, S. Microwave-assisted Claisen rearrangement on a silica gel support, Tetrahedron Lett., 2004, 45, 9603-9605.

29- H. A. Oskooie, M. M. Heravi, A. Sadnia, F. Jannati, F.K. Behbahani, $\mathrm{H}_{2} \mathrm{SO}_{4} /$ Silicagel: Highly Efficient Catalyst for the Synthesis of $\alpha$-Aminonitriles Using Trimethysilyl Cyanide, Monatsh. Chem., 2008, 139, 22-29.

30- E. D. Clarke, Beyond physical propertiesapplication of Abraham descriptors and LFER analysis in agrochemical research, Bioorg. Med. Chem., 2009, 17, 4153-4159.

31- C. Lamberth, S. Jeanmart, T. Luksch, A. Plant, Current Challenges and Trends in the Discovery of Agrochemicals, Science, 2013, 341, 742-746. 